\title{
First Degree Uterine Prolapse
}

National Cancer Institute

\section{Source}

National Cancer Institute. First Degree Uterine Prolapse. NCI Thesaurus. Code C35339.

The uterus has descended above the hymen. 